\title{
Prediction of Martensite Start Temperature for Lightweight Fe-Mn-Al-C Steels
}

\author{
Rui Zhang ${ }^{1}$ - Weisen Zheng ${ }^{1,2} \cdot$ Xavier Veys $^{3}$ - Guido Huyberechts ${ }^{4}$. \\ Hauke Springer $^{5} \cdot$ Malin Selleby ${ }^{1}$
}

Submitted: 30 April 2018/in revised form: 9 July 2018/Published online: 18 July 2018

(C) The Author(s) 2018

\begin{abstract}
A tailor-made thermodynamic database of the Fe-Mn-Al-C system was developed using the CALPHAD approach. The database enables predicting phase equilibria and thereby assessing the resulting microstructures of FeMn-Al-C alloys. Available information on the martensite start $\left(M_{s}\right)$ temperature was reviewed. By employing the $M_{s}$ property model in the Thermo-Calc software together with the new thermodynamic database and experimental $M_{s}$ temperatures, a set of model parameters for the Fe-Mn-AlC system in the $M_{s}$ model was optimised. Employing the newly evaluated parameters, the calculated $M_{s}$ temperatures of the alloys in the Fe-Mn-Al-C system were compared with the available measured $M_{s}$ temperatures. Predictions of $M_{s}$ temperatures were performed for the alloys, Fe-10, 15 and $20 \mathrm{wt} . \% \mathrm{Mn}-x \mathrm{Al}-y \mathrm{C}$. The predictability of the $M_{s}$ model can be further validated when
\end{abstract}

This invited article is part of a special issue of the Journal of Phase Equilibria and Diffusion in honor of Prof. Zhanpeng Jin's 80th birthday. The special issue was organized by Prof. Ji-Cheng (JC) Zhao, The Ohio State University; Dr. Qing Chen, Thermo-Calc Software AB; and Prof. Yong Du, Central South University.

\section{Rui Zhang}

ruizh@kth.se

1 Department of Materials Science and Engineering, KTH Royal Institute of Technology, Stockholm 100 44, Sweden

2 School of Materials Science and Engineering, Shanghai University, Shanghai 200444, People's Republic of China

3 Onderzoekscentrum voor Aanwending van Staal OCAS NV, 9060 Zelzate, Belgium

4 Flamac, a division of SIM, vzw, 9052 Zwijnaarde, Belgium

5 Max-Planck-Institut für Eisenforschung $\mathrm{GmbH}$, 40237 Düsseldorf, Germany new experimental $M_{s}$ temperatures of the Fe-Mn-Al-C system are available.

Keywords CALPHAD $\cdot$ Fe-Mn-Al-C $\cdot$ lightweight steels · martensite start temperature

\section{Introduction}

Lightweight steels have aroused scientific and industrial interest due to their excellent strength and ductility. The Fe-Mn-Al-C system forms a class of lightweight steels that exhibit a good combination of mechanical properties (yield strength: $0.4-1.0 \mathrm{GPa}$, ultimate tensile strength: 0.6$2.0 \mathrm{GPa}$; elongation: $\left.30-100 \%^{[1-7]}\right)$ and weight reduction $\left(1.3 \%\right.$ density reduction per 1 wt. $\% \mathrm{Al}$ addition $\left.{ }^{[4]}\right)$. The promising mechanical properties and low density make them good candidates for producing e.g. automotive body panels and tanks for liquefied natural gas (LNG) and transportation. ${ }^{[8,9]}$ Depending on the balance of the alloying elements, these lightweight steels have either an austenitic or duplex microstructure both exhibiting ultra-highstrength characteristics since austenite gives rise to different strengthening mechanisms. ${ }^{[6,10-13]}$ Stacking fault energy $\left(\gamma_{\mathrm{SFE}}\right)$ has been used to interpret various kinds of mechanisms, such as transformation-induced plasticity (TRIP), twinning-induced plasticity (TWIP) and dislocation glide. Generally, the relative values of $\gamma_{\mathrm{SFE}}$ determining each mechanism are $\gamma_{S F E}^{\text {\&or } \alpha}<\gamma_{S F E}^{\text {twinning }}<\gamma_{S F E}^{\text {slip }}{ }^{[14-16]}$ Martensitic transformation is diffusionless and results in a displacive change of structure, without changing the chemical composition between parent and product phases. Martensite start $\left(M_{s}\right)$ temperature is defined as the temperature at which martensite starts to form. Knowledge of 
$M_{s}$ temperature is of critical importance for steel producers to guide the compositional and microstructural design. Computational materials modelling is an efficient tool in steel production, for example, to predict the transformation temperature, transformation rate and alloying effect on the phase transformation. Technically, being able to describe characteristics of martensitic transformation by using a complete physical model gives a relatively high accuracy. However, one has to consider the complexity of martensitic transformation and that the current knowledge is not mature enough to derive a full physical description. ${ }^{[17]}$ So far, several available methods to predict the $M_{s}$ temperature highly rely on experimental data in order to extract an empirical expression, which can only be applied in a limited range of alloying contents. Consequently, a semi-empirical approach, based on well-established thermodynamic databases and available experimental data on $M_{s}$ temperature, may be the best available option for the prediction of $M_{s}$ temperatures in steels.

When it comes to thermodynamic modelling of martensitic transformation, the Gibbs energy difference between parent and product phase is applied to describe the chemical driving force. In order to form any of either phase, this driving force should bypass the chemical Gibbs energy barrier. The concept of the $T_{O}$ temperature was introduced by Kaufman and Cohen ${ }^{[18]}$ to describe the temperature at which the Gibbs energies of parent and product phases are equal. The martensitic transformation starts at the $M_{s}$ temperature, usually well below $T_{0}$, because the reaction does not occur immediately when martensite becomes thermodynamically more stable than austenite. ${ }^{[19]}$ For example, for the martensitic reaction of FCC $(\gamma)$ to HCP $(\varepsilon)$, each phase has a Gibbs energy dependent on temperature and composition. For a given alloy composition, the Gibbs energies of the two phases are identical at the $T_{0}$ temperature,

$G_{m}^{\gamma}\left(T_{0}\right)=G_{m}^{\varepsilon}\left(T_{0}\right)$

where $G_{m}^{\gamma}$ and $G_{m}^{\varepsilon}$ refer to the molar Gibbs energy of $\gamma$ and $\varepsilon$ respectively.

At any other temperature, the Gibbs energies of FCC and HCP martensites differ with each other, which is used as a quantitative measure of the driving force for the martensitic transformation. As given in the work by Palumbo ${ }^{[19]}$ and Baruj et al., ${ }^{[20]}$ one can obtain the critical driving force as,

$\Delta G_{m}^{*}\left(M_{s}\right)=-\Delta G_{m}^{\gamma-\varepsilon}=G_{m}^{\gamma}-G_{m}^{\varepsilon}$

and for the reverse transformation, the driving force is defined as,

$$
\Delta G_{m}^{*}\left(A_{s}\right)=-\Delta G_{m}^{\varepsilon-\gamma}=G_{m}^{\varepsilon}-G_{m}^{\gamma}
$$

Upon rapid cooling, when a critical driving force reaches a certain value of $\Delta G_{m}^{*}\left(M_{s}\right)$, the $\gamma \rightarrow \varepsilon$ martensitic transformation occurs. Equally, the critical driving force for the reverse $\varepsilon \rightarrow \gamma$ transformation upon heating is defined as $\Delta G_{m}^{*}\left(A_{s}\right)$. The two values are positive as they describe the kinetic barriers or resistances to the transformation. They are generally referred to as 'resistance-to-start-the-transformation' energies (RSTEs). ${ }^{[20]}$

Basically, prediction of $M_{s}$ temperatures aims at finding the temperature at which the available driving force of the transformation can bypass the critical driving force. The critical driving force is usually derived by evaluating a large amount of experimental $M_{s}$ temperatures. The available driving force can be achieved from thermodynamic database in the form of Gibbs energy of the desired phases. Therefore, the accuracy of the thermodynamic database is one of the factors affecting the reliability of predicted $M_{s}$ temperature. The importance of thermodynamic database will be further discussed in the following content.

This work is one part of a European Research Fund for Coal and Steel (RFCS) project entitled as 'screening of tough lightweight Fe-Mn-Al-C steels using high throughput methodologies' (LIGHTOUGH).

In the present work, we briefly introduced a thermodynamic database for the Fe-Mn-Al-C system developed for the LIGHTOUGH project. Based on this database and available experimental $M_{s}$ temperature data, the model parameters in the $M_{s}$ property model in the Thermo-Calc software ${ }^{[21]}$ were optimised. The $M_{s}$ temperatures of the Fe-Mn-Al-C system in the $M_{s}$ property model were calculated and compared with the available experimental $M_{s}$ temperatures. The $M_{s}$ temperatures were predicted for the alloys Fe-10, 15 and 20 wt.\% Mn- $x$ Al- $y C$.

\section{Thermodynamic Database for the Fe-Mn-Al-C System}

Fe-Mn-Al-C based lightweight steel is the core of the present study. A thermodynamic database for this quaternary system was constructed based on the constituent binary and ternary systems. An overview of the systems assessed was described. The Thermo-Calc software ${ }^{[21]}$ was employed in the reviewed assessments unless stated otherwise.

\subsection{Fe-Mn-Al System}

The Fe-Mn-Al system has received large attention which has resulted in experimentally well-determined phase equilibria. In the Al-rich region, a number of intermetallic phases are stable, such as $\mathrm{Al}_{13} \mathrm{Fe}_{4}, \mathrm{Al}_{5} \mathrm{Fe}_{2}, \mathrm{Al}_{2} \mathrm{Fe}$ and 
$\mathrm{Al}_{8} \mathrm{Mn}_{5}$. Fcc and bcc dominate in the Fe-rich part. With the addition of $\mathrm{Al}$ to a critical amount, order/disorder transformations occur and bcc-based $\mathrm{B} 2$ and $\mathrm{DO}_{3}$ form, which may embrittle the steels. Lindahl et al. ${ }^{[22,23]}$ assessed the Fe-Mn-Al system by taking into account these order/disorder transformations. The partitioning model was used to describe the chemical ordering, ${ }^{[23]}$ and the ordering contribution, $\Delta G_{m}^{o r d}$, was added to the disordered part of Gibbs energy, i.e.

$$
\begin{aligned}
& G_{m}=G_{m}^{d i s}\left(x_{i}\right)+\Delta G_{m}^{o r d} \\
& \Delta G_{m}^{\text {ord }}=G_{m}^{\text {ord }}\left(y_{i}\right)-G_{m}^{\text {ord }}\left(y_{i}=x_{i}\right)
\end{aligned}
$$

In addition, when using a four-sublattice (4SL) model to describe bcc, the importance of ternary end-member parameters was addressed and a method to evaluate these end-members was presented. ${ }^{[23]}$ As reported by Hallstedt et al., ${ }^{[24]}$ despite the advantage of using 4SL model to describe the bcc-based phases, the energy difference between $\mathrm{B} 2$ and $\mathrm{DO}_{3}$ is very small in the ternary system, therefore, a two-sublattice model should be sufficient for most practical purposes.

Recently, Balanetskyy et al. ${ }^{[25]}$ and Priputen et al. ${ }^{[26]}$ experimentally investigated the Fe-Mn-Al system with respect to the phase equilibria at the Al-rich region and the isothermal section at $1273 \mathrm{~K}$, respectively. By considering the measurements by Balanetskyy et al. ${ }^{[25]}$ and Priputen et al. ${ }^{[26]}$ and the reassessment of the Fe-Al binary system, ${ }^{[27]}$ Zheng et al. ${ }^{[28]}$ reassessed the Fe-Mn-Al ternary system. In that work the Al-Mn system ${ }^{[28]}$ was also reassessed by introducing stable $\gamma 1$ and metastable $\varphi$ for the first time. Based on the revised thermodynamic parameters, ${ }^{[28]}$ the experimental phase equilibria ${ }^{[25,26]}$ over the whole composition and wide temperature ranges were well reproduced.

\subsection{Al-C-Mn System}

For lightweight steels, the kappa phase plays a significant role in mechanical properties due to its precipitation strengthening effect. However, the Al-C-Mn system is still poorly investigated and scarce experimental data are available. It leads to a difficulty in performing a thermodynamic assessment, especially to obtain a thermodynamic description of the kappa phase. Several attempts were made to model kappa, for example, it has been modelled as $(\mathrm{Mn})_{3}(\mathrm{Al})_{1}(\mathrm{C}, \mathrm{Va})_{1}{ }^{[29]}$ and $(\mathrm{Mn})_{3}(\mathrm{Al}, \mathrm{Mn})_{1}(\mathrm{C}, \mathrm{Va})_{1} .^{[30]}$ Compared with the phase equilibria measurements from Bajenova et al. ${ }^{[31,32]}$ at 1373 and $1473 \mathrm{~K}$, the attempted modelling of the kappa was insufficient as it could not describe its wide homogeneity range. Zheng et al. ${ }^{[33]}$ recently performed a thermodynamic assessment of the AlC-Mn system with a particular attention paid to kappa. It was modelled as an ordered form of fcc as regards to using four substitutional sublattices but with only a quarter of interstitial sites compared to FCC: $(\mathrm{Al}, \mathrm{Mn})_{0.25}(-$ $\mathrm{Al}, \mathrm{Mn})_{0.25}(\mathrm{Al}, \mathrm{Mn})_{0.25}(\mathrm{Al}, \mathrm{Mn})_{0.25}(\mathrm{C}, \mathrm{Va})_{0.25}$. Ab initio calculations were carried out at $0 \mathrm{~K}$ for the end-members of kappa. Based on the acquired thermodynamic parameters, ${ }^{[33]}$ the calculated isothermal sections at 1373 and $1473 \mathrm{~K}$ were consistent with the experimental data from Bajenova et al. ${ }^{[31,32]}$

\subsection{Fe-Al-C System}

The Fe-Al-C system has been extensively investigated and a literature review on this ternary system can be found in the recent assessment work by Zheng et al. ${ }^{[27]}$ The partitioning model was employed to describe the order/disorder transformations, as expressed in Eq 4 and 5. Additionally, the first-principle calculation was made to obtain reliable enthalpies of formation of the ordered phases in this ternary system. Using the already described sublattice model for kappa, ${ }^{[33]}$ Zheng et al. ${ }^{[27]}$ well reproduced the wider compositional range that was measured by Phan et al. ${ }^{[34]}$ and Palm and Inden. ${ }^{[35]}$ As can be seen in Fig. 1, compared with the assessment work by Phan et al. ${ }^{[34]}$ and Connetable et al., ${ }^{[36]}$ Zheng et al. ${ }^{[27]}$ made a substantial improvement of the description of kappa.

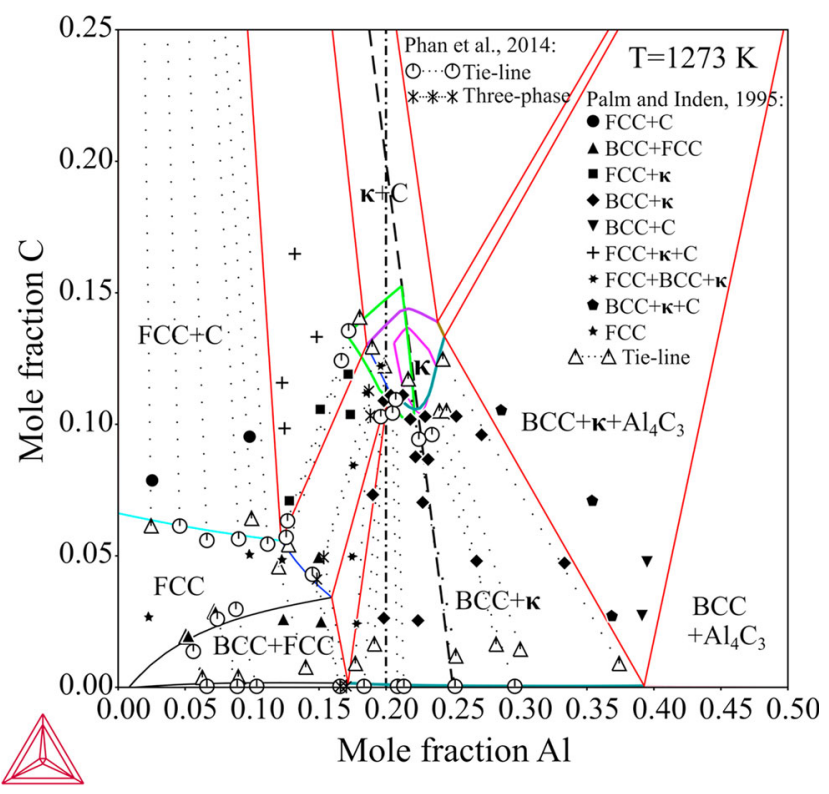

Fig. 1 Comparison among the calculated isothermal section at $1273 \mathrm{~K}$ by Zheng et al., ${ }^{[27]}$ Phan et al. ${ }^{[34]}$ and Connetable et al. ${ }^{[36]}$ for the Fe-Al-C system. The solid green and magenta lines are the phase boundary of kappa calculated by Phan et al. ${ }^{[34]}$ and Connetable et al., ${ }^{[36]}$ respectively. The dashed and dash-dotted lines denote $x_{\mathrm{Fe}} / x_{\mathrm{Al}}=3$ and $x_{\mathrm{Al}}=0.2$, respectively, which denotes the limitation of the earlier descriptions for kappa. ${ }^{[34,36]}$ The Figure is reprinted with the permission from Zheng et al. ${ }^{[27]}$ 


\subsection{Fe-Mn-C System}

Huang ${ }^{[37]}$ performed a thermodynamic assessment of this ternary system using the CALPHAD approach. The thermodynamic description is widely accepted since it well reproduces most of the characteristics of this ternary system except for a poor agreement with the liquidus surface projection determined by Schürmann and Geissler. ${ }^{[38]}$ Later, Djurovic et al. ${ }^{[39]}$ conducted a thermodynamic re-evaluation of the $\mathrm{Fe}$ Mn-C system. They improved the thermodynamic description of the liquid phase so it fits better with the experimental liquidus data ${ }^{[38]}$ in comparison with the work by Huang. ${ }^{[37]}$ Additionally, Djurovic et al. ${ }^{[39]}$ did ab initio calculations of the enthalpies of formation for the metastable carbides, which gave a reasonable description of carbide equilibria at low temperatures. Therefore, the assessment by Djurovic et al. ${ }^{[39]}$ was adopted in constructing the present thermodynamic database of the Fe-Mn-Al-C system.

\subsection{Fe-Mn-Al-C System}

As has been reviewed above, thermodynamic descriptions of the ternary systems $\mathrm{Fe}-\mathrm{Mn}-\mathrm{Al}, \mathrm{Al}-\mathrm{C}-\mathrm{Mn}$ and $\mathrm{Fe}-\mathrm{Al}-\mathrm{C}$ were improved in a series of work by Zheng et al. ${ }^{[27,28,33]} \mathrm{By}$ taking the thermodynamic description of $\mathrm{Fe}-\mathrm{Mn}-\mathrm{C}$ from
Djurovic et al., ${ }^{[39]}$ a tailor-made thermodynamic database for the LIGHTOUGH project was constructed in the present work. Hallstedt et al., ${ }^{[24]}$ Chin et al. ${ }^{[29]}$ and Kim and Kang ${ }^{[30]}$ previously reported thermodynamic descriptions of the $\mathrm{Fe}$ Mn-Al-C system. Hallstedt et al. ${ }^{[24]}$ pointed out that a simplified model for kappa adopted in the works ${ }^{[24,29,30]}$ should be replaced by a model capable of describing order/disorder transformations. This improvement has been made in this new thermodynamic database. Within the LIGHTOUGH project, the thermodynamic database has been applied to guide the selection of alloys to be cast, to estimate the possible formation of stable phases at desired temperatures and to predict $M_{s}$ temperatures for the alloys of interest.

\section{Methods for Predicting $M_{s}$ Temperature}

The prediction of $M_{s}$ temperature in the current work is based on an unreleased beta version of a Martensite Property Model in Thermo-Calc software. ${ }^{[21]}$ This $M_{s}$ property model was developed on the basis of the work by Stormvinter et al. ${ }^{[17]}$ and Borgenstam and Hillert. ${ }^{[40]}$ The core is to derive the expression of the chemical barrier of martensitic transformation and then find the temperature where available driving force equals the barrier. Certainly,

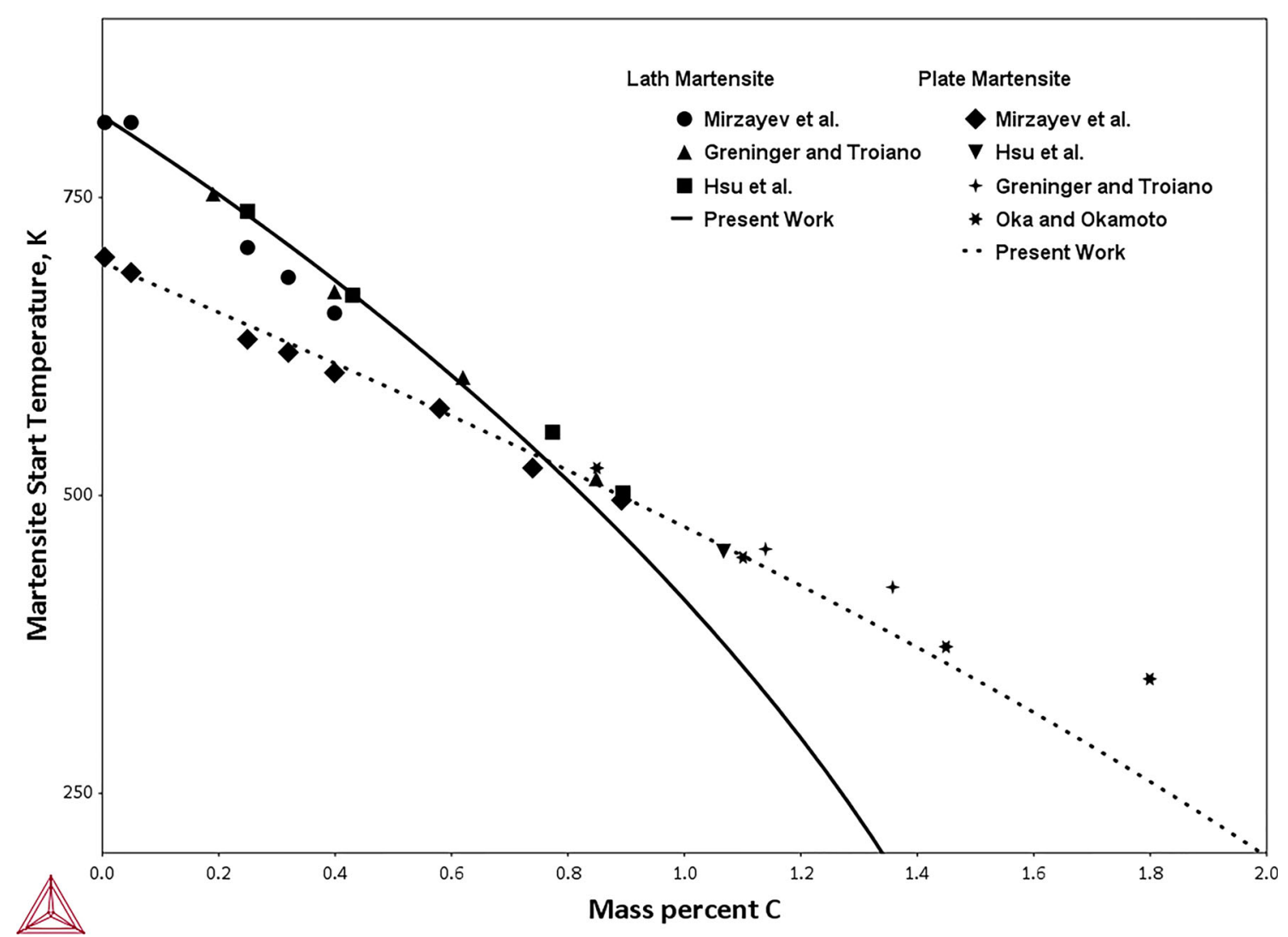

Fig. 2 Calculated $M_{s}$ temperatures of $\gamma \rightarrow \alpha$ martensitic transformation in the Fe-C binary system compared with the experimental data ${ }^{[46-49]}$ 


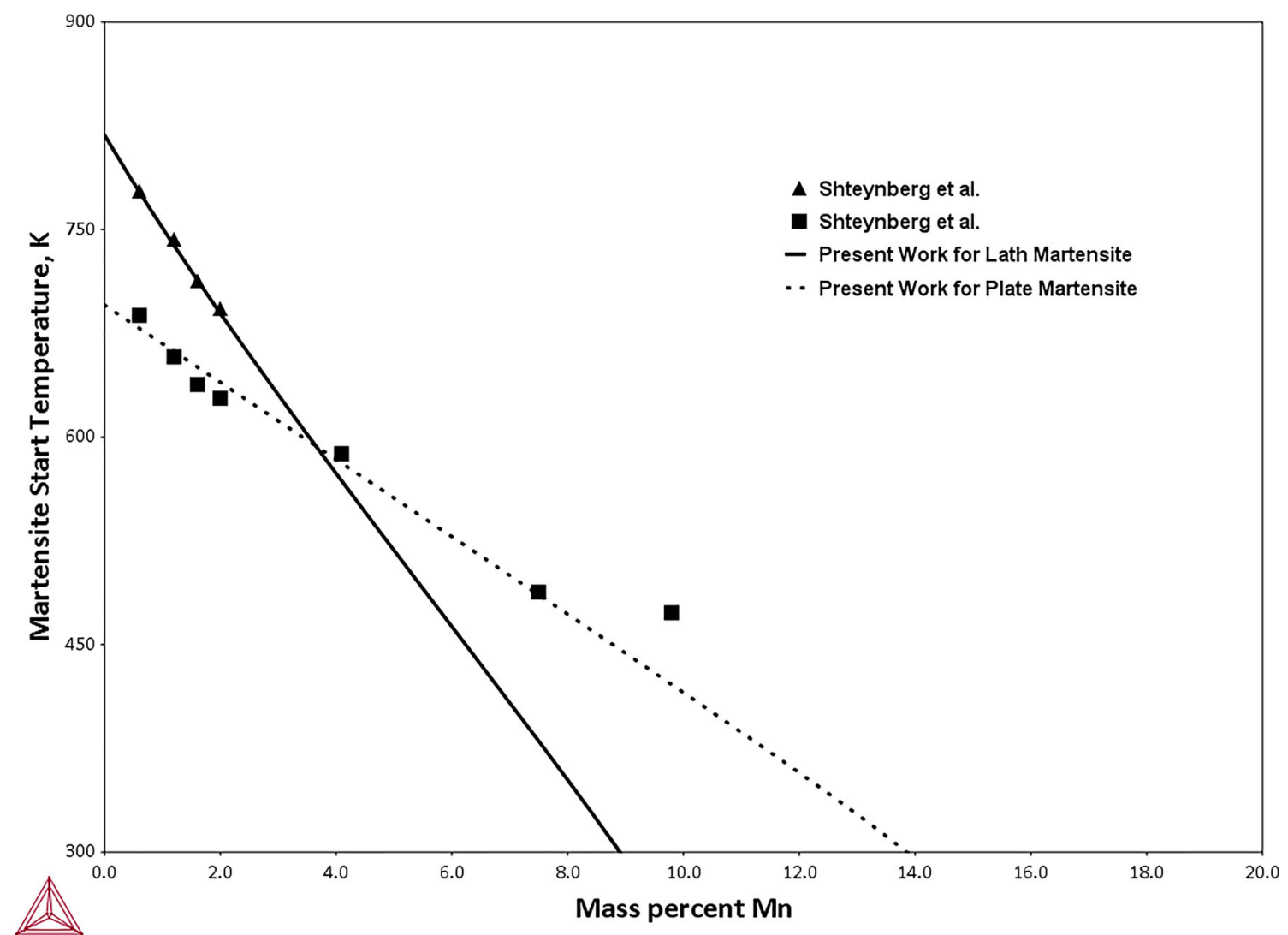

Fig. 3 Calculated $M_{s}$ temperatures of $\gamma \rightarrow \alpha$ martensitic transformation in the Fe-Mn binary system compared with the experimental data ${ }^{[50]}$

several other methods are available to predict $M_{s}$ temperatures. Some representative ones will be briefly reviewed and the current approach elaborated.

\subsection{Empirical Method}

As has been demonstrated in the work by Peet, ${ }^{[41]}$ multiple linear regression equations were employed to summarise the influence of various alloying elements on the martensite start temperature. The general expression is as,

$M_{s}=k_{0}+\sum k_{i} w_{i}$

where $k_{0}$ is the $M_{s}$ temperature of pure iron, $w_{i}$ is the concentration of element $i$ (usually in weight percentage), and $k_{i}$ is the parameter relating to the concentration of each element to the change in the $M_{s}$ temperature.

Although this method can predict the trend of the $M_{s}$ temperature in a simple way, it is only applicable in a certain composition range of a certain system and can hardly provide insight into the mechanism of martensitic transformation. One representative work was carried out by Izumiyama et al., ${ }^{[42]}$ that even in binary alloy systems, there is no uniform linear dependence with compositions for various binary systems. Therefore, this method is mere statistical without considering any physical, thermodynamic or microstructural contribution.

This empirical method was improved by Wang et al. ${ }^{[43]}$ incorporating the effect of binary interactions. The nominal concentration of binary terms is defined as the square root of two chemical compositions,

$w_{i-j}=\sqrt{w_{i} w_{j}}$

So $\mathrm{Eq} 6$ can be revised as,

$M_{s}=k_{0}+\sum k_{i j} \sqrt{w_{i} w_{j}}$

According to Wang et al., ${ }^{[43]}$ using Eq 8, the standard error in predicting the $M_{s}$ temperature is as low as $4.2{ }^{\circ} \mathrm{C}$.

\subsection{Thermodynamic Method}

Forsberg and Åren ${ }^{[44]}$ performed a thermodynamic assessment of the Fe-Mn-Si system and calculated the $M_{s}$ and $A_{s}$ temperatures of the $\gamma \rightarrow \varepsilon$ martensitic transformation. On a tentative basis, they chose the value of $-50 \mathrm{~J} / \mathrm{mol}$ for the Gibbs energy difference between HCP and FCC at the experimentally determined $M_{s}$ temperature. 


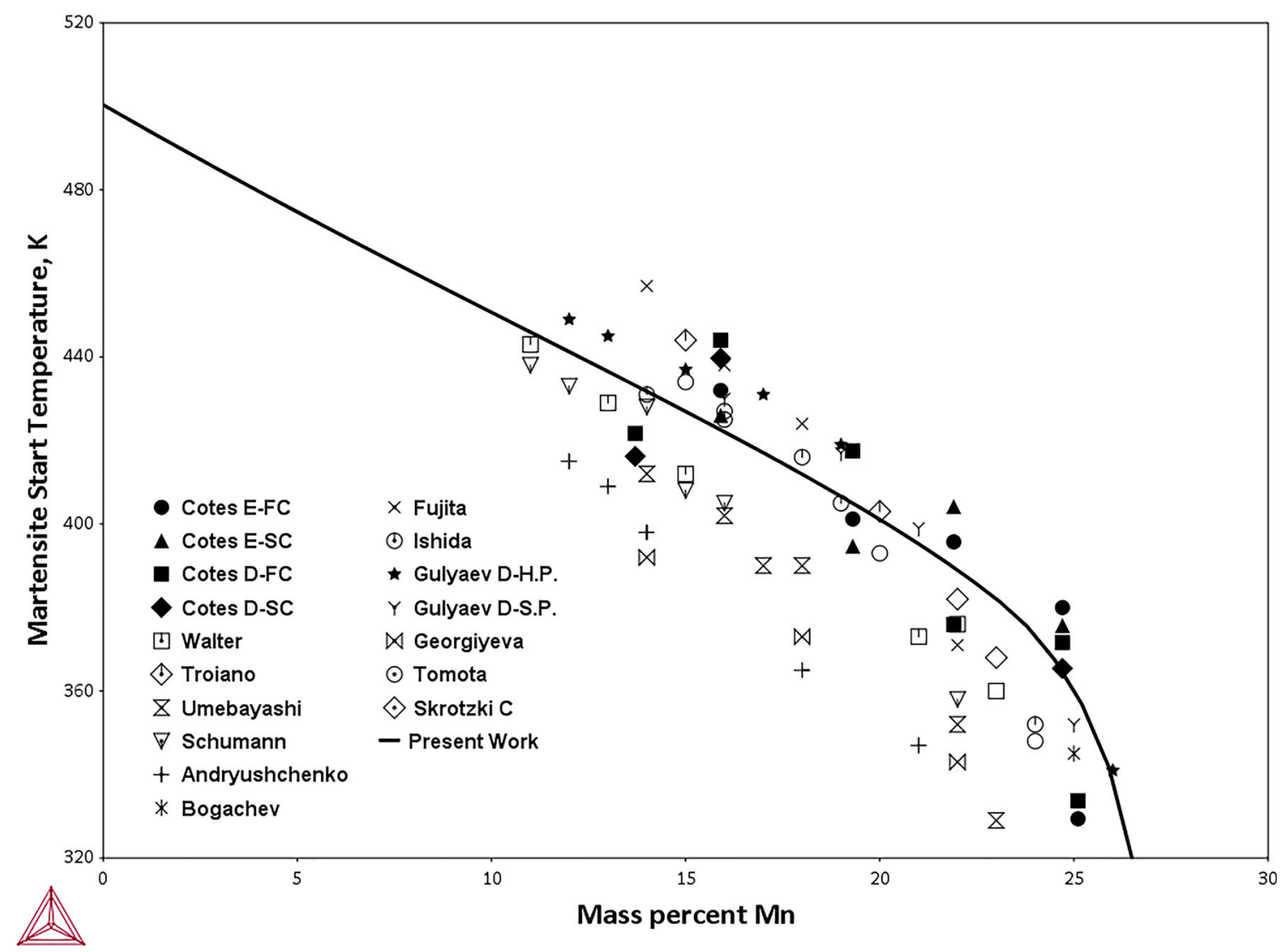

Fig. 4 Calculated $M_{s}$ temperatures of $\gamma \rightarrow \varepsilon$ martensitic transformation in the Fe-Mn binary system compared with the experimental data. ${ }^{[51,52]}$ All the experimental data included in this comparison is accessible from the work by Cotes et al. ${ }^{[51]}$

Based on the assessed thermodynamic database and the quantity of $G_{m}^{h c p}-G_{m}^{f c c}=-50 \mathrm{~J} / \mathrm{mol}$, the $M_{s}$ and $A_{s}$ temperatures of the $\gamma \rightarrow \varepsilon$ martensitic transformation were calculated and compared. The agreement is less satisfactory at higher Mn content, possibly due to an incomplete description of the HCP phase. ${ }^{[19]}$ Cotes et al. ${ }^{[45]}$ improved the descriptions of the $G_{m}$ functions of various phases, based on which the $M_{s}$ and $A_{s}$ temperatures were predicted with a good agreement with extensive experimental results. Therefore, one may conclude that the accuracy of the thermodynamic database largely determines the reliability of the predictions of the $M_{s}$ temperature.

\subsection{Semi-Empirical Method: the Present Approach}

Borgenstam and Hillert ${ }^{[40]}$ reviewed a number of $M_{s}$ temperature data for $\mathrm{Fe}-\mathrm{X}$ systems and accepted the results from rapid cooling experiments, where a range of cooling rates that show a constant martensitic transformation temperature, can be considered as $M_{s}$ temperatures. They calculated the driving forces for the formation of the two kinds of martensites (lath and plate), as expressed in Eq 9 and 10. They found that the driving force for the $\gamma \rightarrow \alpha$ transformation may not be much influenced by solution hardening but may mainly be a function of temperature.

$\Delta G_{m}^{\gamma \rightarrow \alpha}=3640-2.92 * T(K) \quad$ (lath martensite, $\mathrm{J} / \mathrm{mol}$ )

$\Delta G_{m}^{\gamma \rightarrow \alpha}=2100 \quad($ plate martensite, $\mathrm{J} / \mathrm{mol})$

Based on the derived driving forces in Eq 9 and 10 by Borgenstam and Hillert, ${ }^{[40]}$ Stormvinter et al. ${ }^{[17]}$ extended their work into the expression as a function of temperature and composition, in order to predict the $M_{s}$ temperature of commercial steels. A sufficient chemical driving force is required to bypass the barrier in order to initiate the martensitic transformation. The barrier in their work ${ }^{[17]}$ is represented as,

$\Delta G_{m}^{* \gamma \rightarrow \alpha}=\sum_{M} u_{M}\left(1-u_{C}\right) \Delta G_{M V a}^{*}+\sum_{M} u_{M} u_{C} \Delta G_{M C}^{*}$

where $V a$ stands for vacant interstitials and $M$ for a substitutional element. $\Delta G_{M V a}^{*}$ and $\Delta G_{M C}^{*}$ are the hypothetical barriers for pure $M$ and component $M C$, respectively. $u_{M}$ and $u_{C}$ are concentration variables. The final expression can be obtained per mole of atoms, 


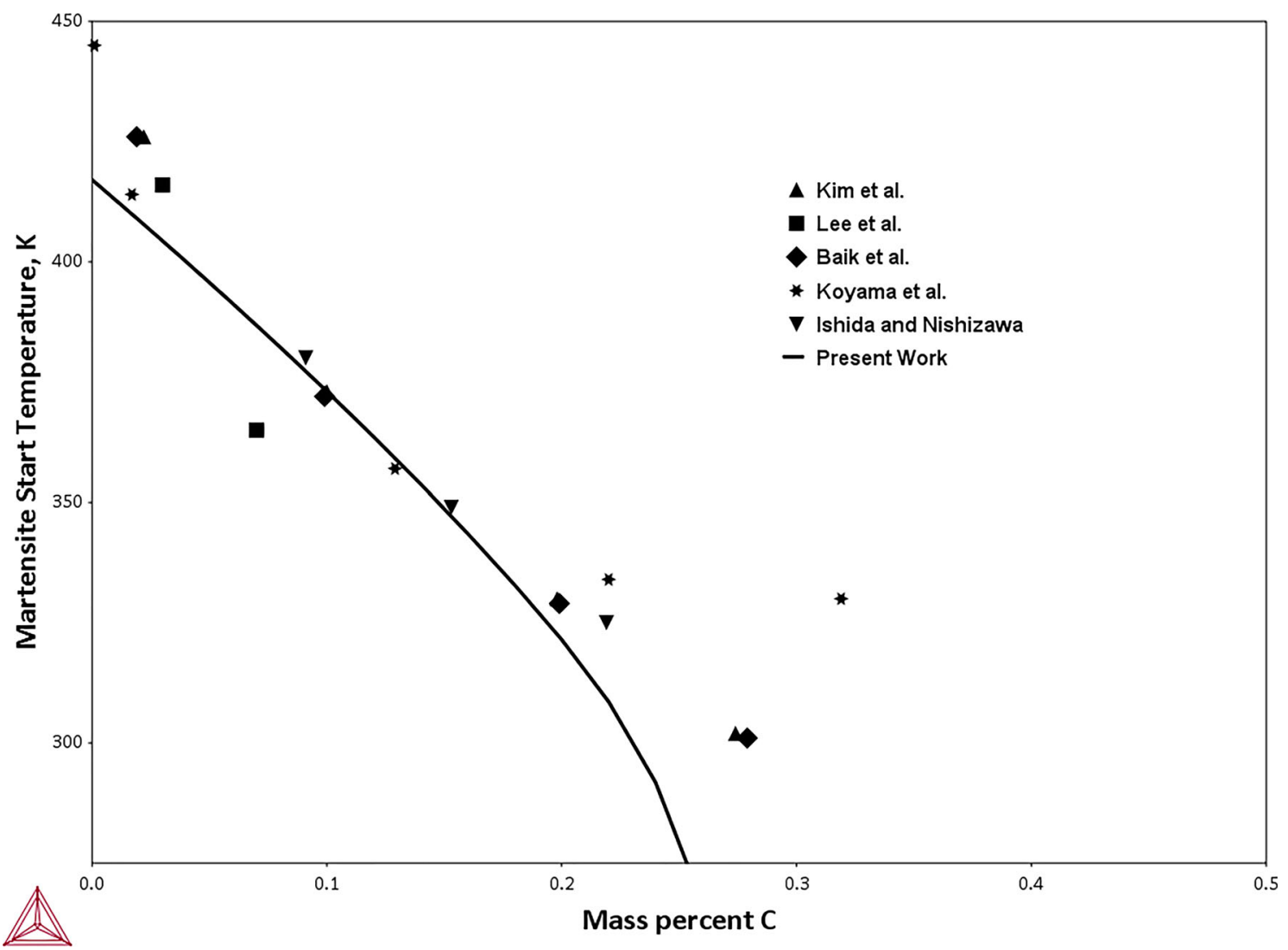

Fig. 5 Calculated $M_{s}$ temperatures of $\gamma \rightarrow \varepsilon$ martensitic transformation in the $\mathrm{Fe}-17 \mathrm{wt} . \% \mathrm{Mn}-x \mathrm{C}$ system compared with the experimental data ${ }^{[55-59]}$

$$
\begin{aligned}
\Delta G_{m}^{* \gamma \rightarrow \alpha} & =\Delta G_{\mathrm{FeV} a}^{*}+x_{C}\left(K_{C}-\Delta G_{\mathrm{FeVa}}^{*}\right) \\
& +\sum_{M \neq F e} x_{M} K_{M}+x_{C} \sum_{M \neq F e} \frac{x_{M}}{1-x_{C}} K_{M C}
\end{aligned}
$$

The physical meaning of the three types of coefficients is as follows, ${ }^{[17]} K_{C}$ denotes the change in barrier per mole of carbon atoms that is added; $K_{M}$ denotes the change in the barrier when $1 \mathrm{~mol}$ of iron is exchanged with $1 \mathrm{~mol}$ of $M$; and $K_{M C}$ stands for a ternary effect when $1 \mathrm{~mol}$ of carbon is added at the same time as $1 \mathrm{~mol}$ of iron is exchanged with $1 \mathrm{~mol}$ of $M$.

According to Stormvinter, ${ }^{[1]}$ a linear superposition law was assumed for the combined effect of alloying elements on the driving force. Based on this assumption, it yields the following expressions to be applied for predicting $M_{s}$ temperature of steels. To be consistent with the alloying elements in the LIGHTOUGH project, therefore, the expressions below only consider elements $\mathrm{Fe}, \mathrm{Mn}, \mathrm{Al}$ and $\mathrm{C}$,

$$
\begin{aligned}
\Delta G_{m(\text { Lath })}^{* \gamma \rightarrow \alpha}= & 3640-2.92 M_{s}+L_{C}^{1} x_{C}+L_{C}^{2} \frac{x_{C}^{2}}{\left(1-x_{C}\right)} \\
& +L_{M n} x_{M n}+L_{A l} x_{A l}
\end{aligned}
$$

$$
\begin{aligned}
& \Delta G_{m(\text { Plate })}^{* \gamma \rightarrow \alpha}=2100+L_{C}^{1} x_{C}+L_{C}^{2} \frac{x_{C}^{2}}{\left(1-x_{C}\right)}+L_{M n}^{1} x_{M n} \\
& +L_{A l}^{1} x_{A l}+L_{A l}^{2} \frac{x_{A l}^{2}}{\left(1-x_{C}\right)} \\
& \Delta G_{m}^{* \gamma \rightarrow \varepsilon}=C_{e p s i l o n}+L_{C}^{1} x_{C}+L_{C}^{2} \frac{x_{C}^{2}}{\left(1-x_{C}\right)} \\
& +L_{M n}^{1} x_{M n}+L_{M n}^{2} \frac{x_{M n}^{2}}{\left(1-x_{C}\right)}+L_{M n}^{3} \frac{x_{M n}^{3}}{\left(1-x_{C}\right)}+L_{A l} x_{A l} \\
& +L_{M n, A l}^{1} \frac{x_{M n} x_{A l}}{\left(1-x_{C}\right)}+L_{M n, C}^{1} \frac{x_{M n} x_{C}}{\left(1-x_{C}\right)}
\end{aligned}
$$

where $L_{M}^{1}$ and $L_{M}^{2}(M=\mathrm{Mn}, \mathrm{C}$ and $\mathrm{Al})$ are the first and second order binary interaction parameters for each martensitic transformation, $L_{M, N}^{1}$ is the first order ternary interaction parameter in which $M$ and $N$ are two alloying elements in the steel and $C_{\text {epsilon }}$ is a constant. In the present work, the interaction parameters and constant were optimised based on available experimental $M_{s}$ temperatures. 


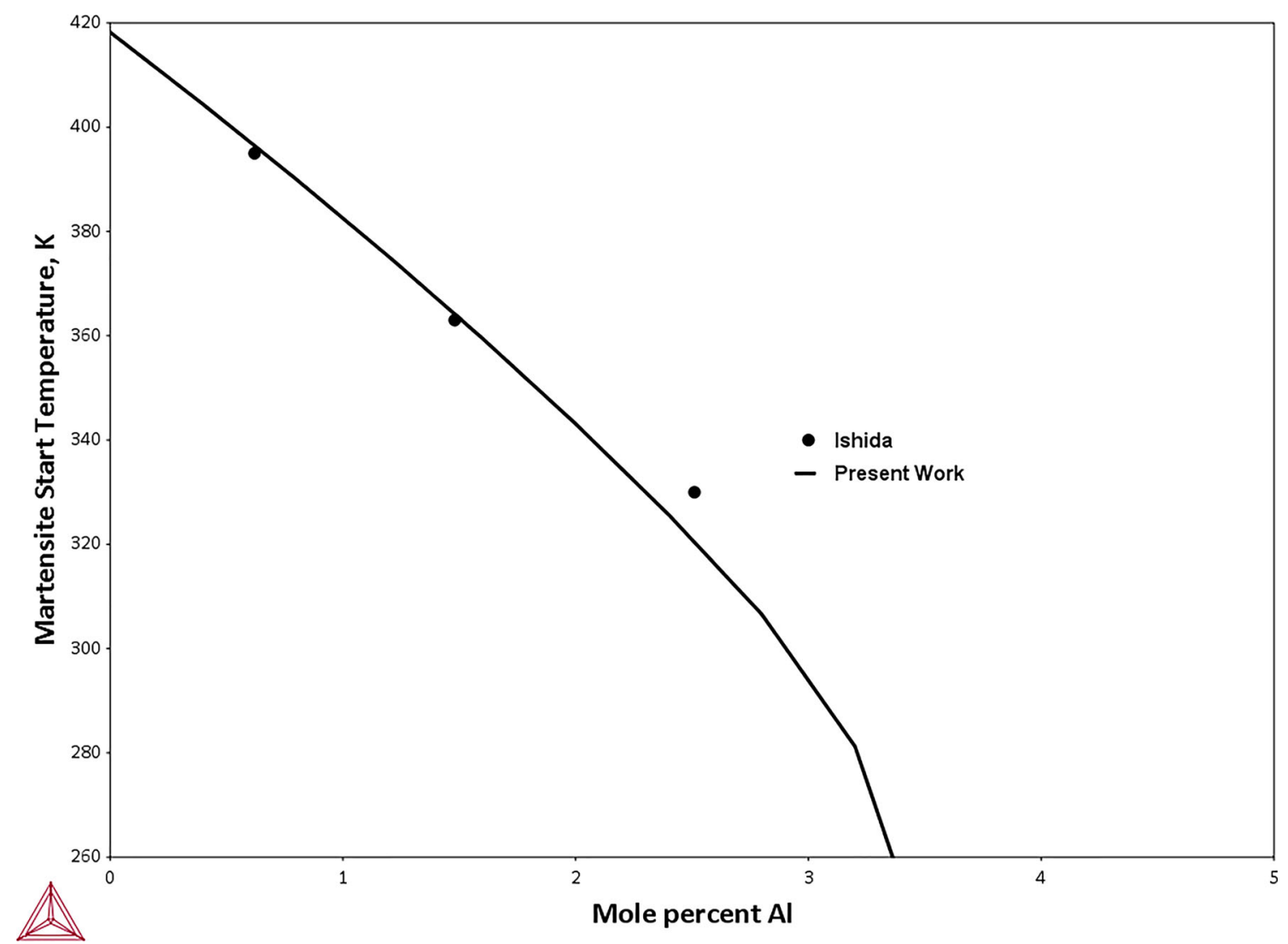

Fig. 6 Calculated $M_{s}$ temperatures of $\gamma \rightarrow \varepsilon$ martensitic transformation in the $\mathrm{Fe}-17$ at.\% $\mathrm{Mn}-x \mathrm{Al}$ system compared with the experimental data. ${ }^{[59]}$

\section{Calculations and Predictions of $M_{s}$ Temperature for Selected Alloys}

By using the Eq 13-15 and our thermodynamic database for the Fe-Mn-Al-C system, which have been included in the $M_{s}$ property model in Thermo-Calc software, ${ }^{[21]}$ it enables finding the temperature where the available driving force for each alloy equals the required driving force or chemical barrier. Combined with a wide selection of measured $M_{s}$ temperatures, the interaction parameters in the $M_{s}$ property model in Thermo-Calc software ${ }^{[21]}$ were adjusted. The dilatometer measurements performed in the LIGHTOUGH project were also used to fit the model parameters. Figure 2, 3, 4, 5, 6 and 7 show the comparisons between the calculated $M_{s}$ temperatures and experimental data used for optimising the binary and ternary interaction parameters. Obviously, one can observe the scattered experimental $M_{s}$ temperatures, which may be attributed to different methods employed to measure $M_{s}$ temperatures that bring about the difficulty in judging uncertainty limits for the reported $M_{s}$ temperatures. Notwithstanding, the calculations can well reproduce the experimental $M_{s}$ temperatures.

\subsection{Fe-C Binary System}

Based on $M_{s}$ temperatures measured by Ref $46-48$ and thermodynamic database created in the present work, first and second order interaction parameters in $\mathrm{Eq} 13$ for lath martensite were optimised. Using the same method, the parameters in $\mathrm{Eq} 14$ for plate martensite were fitted to the experimental $M_{s}$ temperatures from Ref 46-49. During optimisation, more focus was placed on fitting to the experimental $M_{s}$ temperatures at low carbon contents considering the significance of commercial steels. The calculated $M_{s}$ temperatures for lath and plate martensites were compared with experimental data and shown in Fig. 2.

\subsection{Fe-Mn Binary System}

Depending on the content of $\mathrm{Mn}$ and the rate of cooling, different martensitic transformations take place. Upon rapid cooling, at low $\mathrm{Mn}$ content, $\gamma$ transforms into $\alpha$ martensite and at high Mn content, $\varepsilon$-martensite forms. By using the newly optimised parameters in the $M_{s}$ model, the calculated $M_{s}$ temperatures of $\gamma \rightarrow \alpha$ and $\gamma \rightarrow \varepsilon$ 


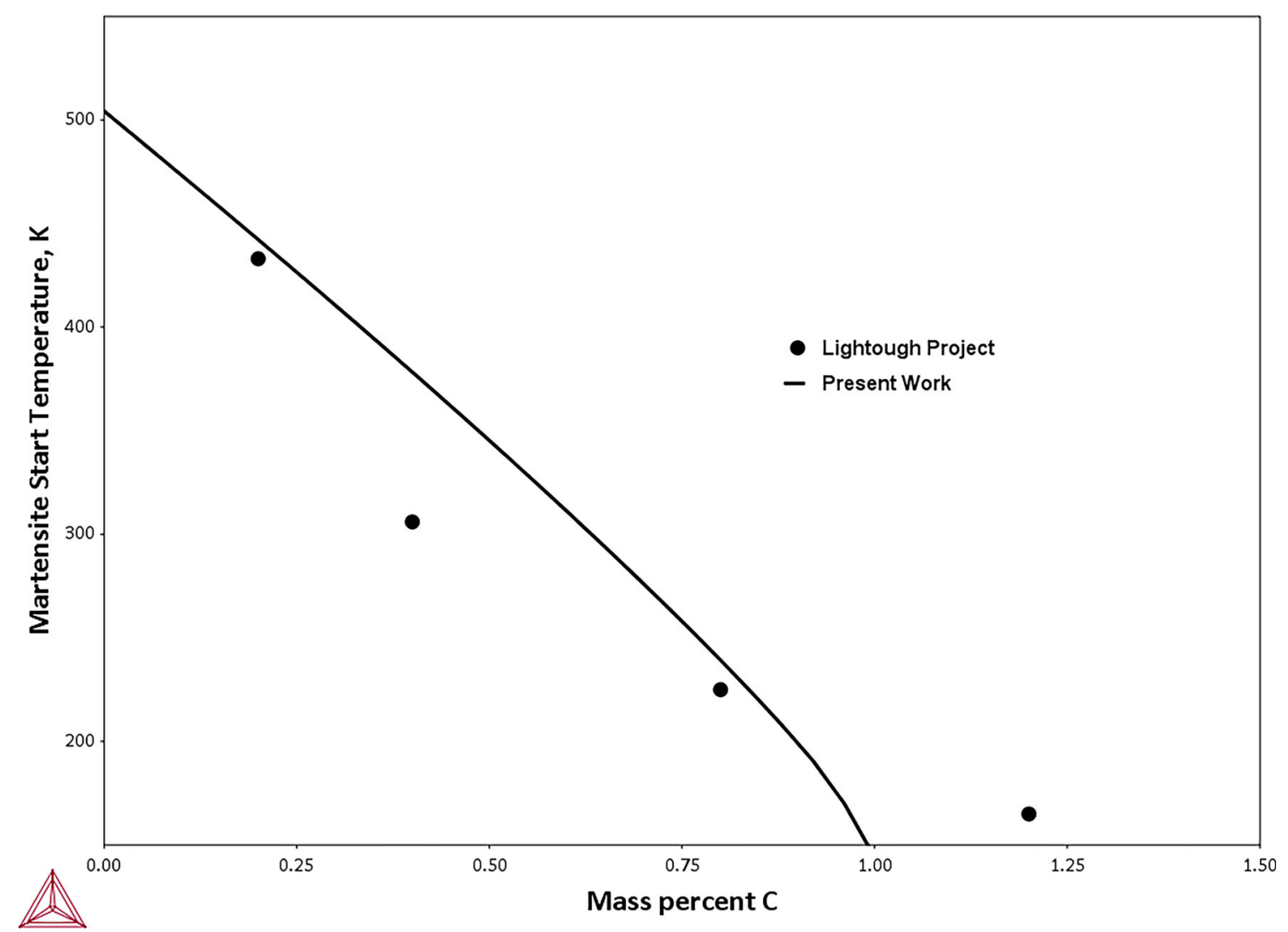

Fig. 7 Calculated $M_{s}$ temperatures of $\gamma \rightarrow \varepsilon$ martensitic transformation in the Fe-10Mn-6Al-xC (wt.\%) system compared with the data measured in the LIGHTOUGH project

transformations were presented in Fig. 3 and 4 along with the experimental data. ${ }^{[50,51]}$ With an increased amount of $\mathrm{Mn}$, a decrease of the $M_{s}$ temperature can be observed for both types of martensitic transformations. The $M_{s}$ temperature of $\varepsilon$-martensite transformation has been extensively studied and the results show a considerable scatter. The previously measured $M_{s}$ temperatures have been reviewed and compiled in the work by Cotes et al. ${ }^{[51]}$ One of the reasons for the large discrepancy is the presence of impurities. Gulyaev et al. ${ }^{[52]}$ measured the $M_{s}$ temperature of $\varepsilon$-martensite in the Fe-Mn system using a dilatometry method and the alloys were prepared with different degrees of purity, obtained by vacuum melting and open melting, respectively. It was found that increasing the purity of FeMn alloys raised the $M_{s}$ temperature of the $\gamma \rightarrow \varepsilon$ transformation ${ }^{[52]}$ so that a larger quantity of $\varepsilon$ martensite was formed. Another reason that may influence the measured $M_{s}$ temperature is the measuring techniques. Cotes et al. ${ }^{[51]}$ performed an experimental study of the $M_{s}$ temperature in the Fe-Mn system (10-30 wt.\% Mn) by two complementary techniques, dilatometry and electrical resistivity measurements. Differences of the measured $M_{s}$ temperatures were observed for the two techniques.

\subsection{Fe-Mn-C and Fe-Mn-Al Ternary Systems}

Fe-Mn alloys were reported to show a good damping capacity caused by forming $\varepsilon$-martensite upon rapid cooling ${ }^{[53,54]}$ in which a $\mathrm{Fe}-17$ wt.\% Mn alloy was proved to exhibit the highest damping capacity in the Fe-Mn alloy system. Therefore, a series of studies was carried out investigating the influence of carbon on $\gamma \rightarrow \varepsilon$ transformation with the addition of carbon into $\mathrm{Fe}-17$ wt.\% $\mathrm{Mn}$ alloy. ${ }^{[55-58]}$ Additionally, Ishida and Nishizawa ${ }^{[59]}$ performed a dilatometer measurement to determine the effects of alloying elements on the $M_{s}$ temperature of $\gamma \rightarrow \varepsilon$ transformation. The effect of $\mathrm{C}$ and $\mathrm{Al}$ were investigated in $\mathrm{Fe}-17$ at.\% $\mathrm{Mn}$ alloy in their work. ${ }^{[59]}$ All these experimental $M_{s}$ temperatures were considered in the optimisation of interaction parameters. As shown in Fig. 5, the $M_{s}$ temperatures of $\gamma \rightarrow \varepsilon$ transformation for the Fe-17 wt.\% $\mathrm{Mn}-x \mathrm{C}$ alloys were predicted and compared with the available measurements. A compromise was made to fit with most of the data at low carbon content due to industrial significance. In Fig. 6, the calculated $M_{s}$ temperatures for the $\gamma \rightarrow \varepsilon$ transformation of $\mathrm{Fe}-17$ at.\% $\mathrm{Mn}-x \mathrm{Al}$ is compared with experimental $M_{s}$ temperatures. 


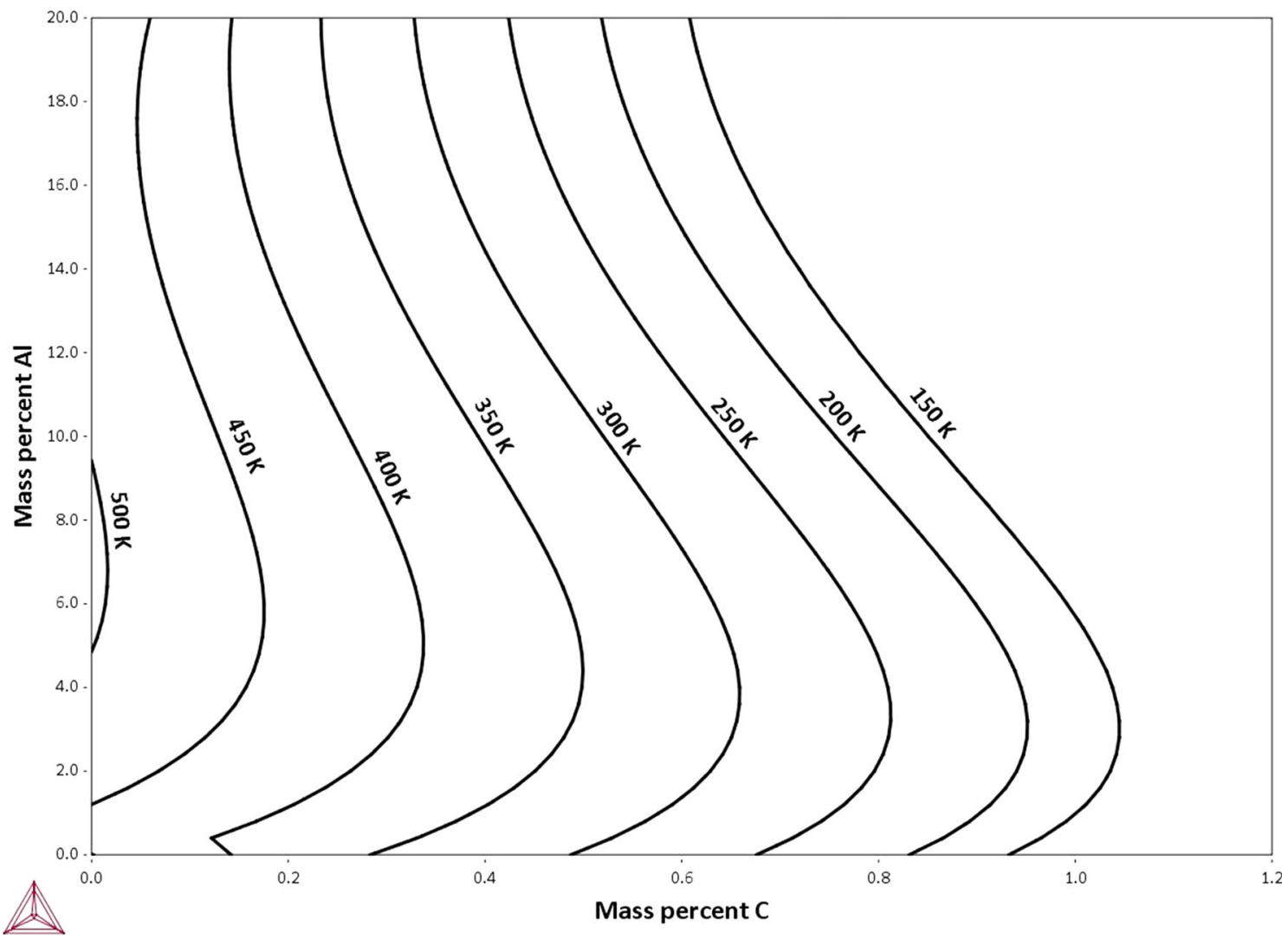

Fig. 8 Predicted $M_{s}$ temperatures for the alloy of Fe-10 wt.\% Mn- $x$ Al- $y \mathrm{C}$

\subsection{Fe-Mn-Al-C}

Within the LIGHTOUGH project, dilatometry experiments were carried out on a selection of alloys, Fe- $10 \mathrm{Mn}-x \mathrm{Al}-y \mathrm{C}$ $(x=3,6,9$ and $12 \mathrm{wt} . \%$, and $y=0,0.2,0.4,0.8$ and 1.2 wt.\%). Fast cooling to cryogenic temperatures was performed with the aim at detecting the $M_{s}$ temperatures. The thermal cycle employed is listed below,

- Slow heating to $1150{ }^{\circ} \mathrm{C}$ at $1{ }^{\circ} \mathrm{C} / \mathrm{s}$, to observe heating transformations.

- The soaking period at $1150{ }^{\circ} \mathrm{C}$ for $2 \mathrm{~min}$. It is assumed that after soaking for $2 \mathrm{~min}$ at $1150{ }^{\circ} \mathrm{C}$, that pseudoequilibrium has been reached.

- Slow cooling to room temperature at $-1{ }^{\circ} \mathrm{C} / \mathrm{s}$, to observe cooling transformations.

- Reheating to $1150{ }^{\circ} \mathrm{C}$ at $10{ }^{\circ} \mathrm{C} / \mathrm{s}$.

- Soaking for $2 \mathrm{~min}$.

- Fast cooling at $-100{ }^{\circ} \mathrm{C} / \mathrm{s}$ (or as fast as possible given the machine limitations) with liquid nitrogen to $-180^{\circ} \mathrm{C}$, to force martensitic transformation if feasible.

Great difficulties were encountered in interpreting the dilatation effect in the dilatometry curves of the selected alloys. The dilatation in the curves was too small to pinpoint the exact start temperatures for the selected alloys. Only for the alloy group of Fe-10Mn-6Al-yC (wt.\%), the transformation was clearly observed and considered in the current optimisation. The calculated results are shown and compared the experimental data in Fig. 7. Based on the optimised model parameters for the Fe-Mn-Al-C system, $M_{s}$ temperatures for the alloys, Fe-(10, 20 and 30 wt.\%)Mn- $x \mathrm{Al}-y \mathrm{C}$, were predicted. Further experimental information is needed to improve the predictability of the current available parameters.

\section{Discussion}

When predicting $M_{s}$ temperatures of a steel, one should use the same thermodynamic database which was adopted when deriving the expression of the required driving force. Otherwise, we would produce meaningless predictions. When the thermodynamic database is updated, the coefficients of alloying elements in the driving force should be re-evaluated accordingly. As has been emphasised by Stormvinter et al., ${ }^{[17]}$ this rule is common to all the models that are linked with thermodynamic databases. Additionally, it should be addressed that the expressions of required driving force in the present work and the work by 


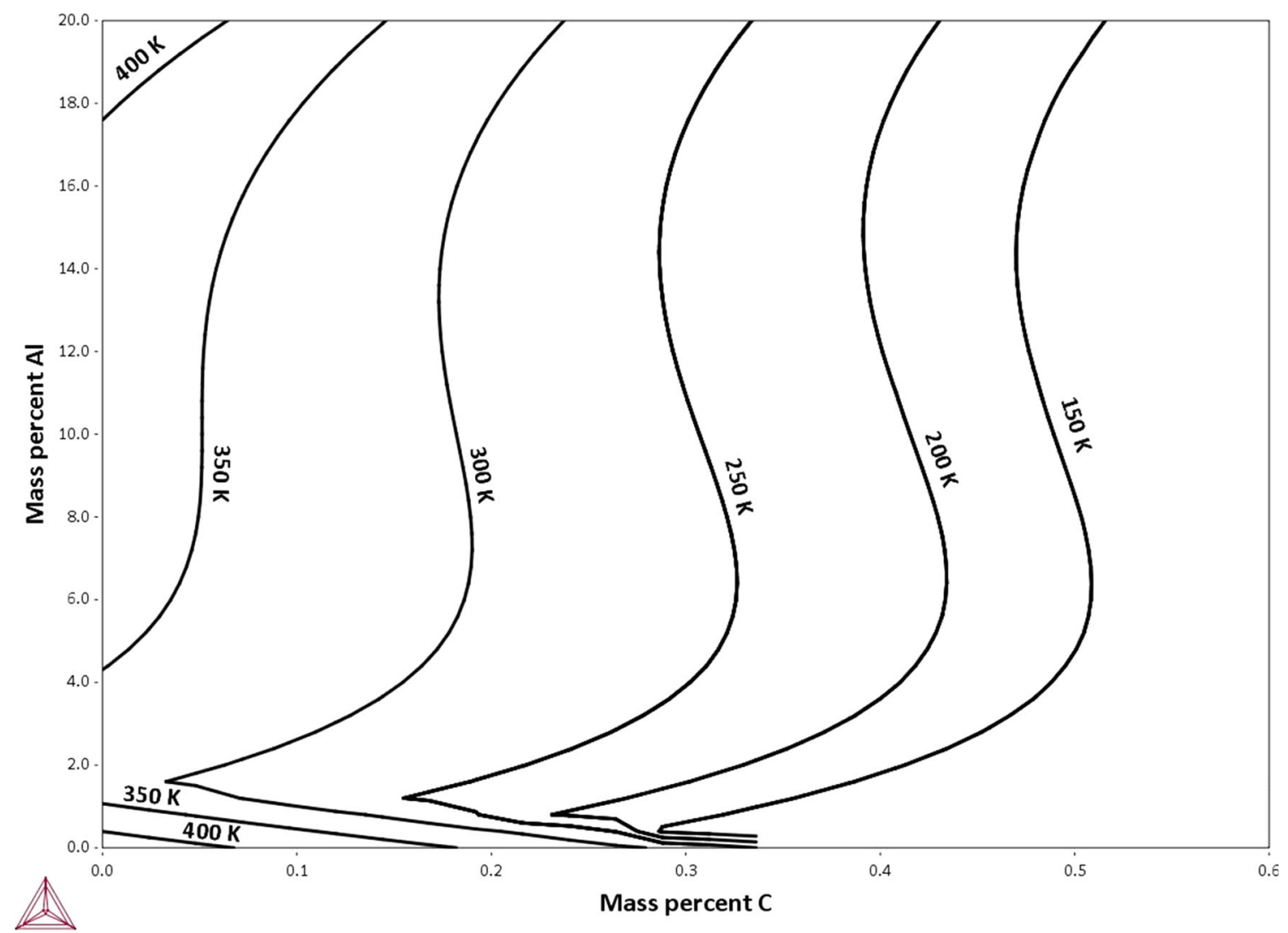

Fig. 9 Predicted $M_{s}$ temperatures for the alloy of Fe-15 wt.\% Mn- $x \mathrm{Al}-y \mathrm{C}$

Stormvinter et al. ${ }^{[17]}$ are all based on the expressions for pure Fe. ${ }^{[40]}$ Accordingly, the description of the critical driving force of pure Fe largely determines the effects of alloying elements and then the final predictions of $M_{s}$ temperatures.

A discontinuous variation of martensitic transformation with increased cooling rate in several alloying systems was reviewed by Stormvinter et al. ${ }^{[17]}$ that the transition from plateau III to IV with the increased cooling rate in iron was reported. In the work by Mirzayev et al. ${ }^{[60]}$ and Wilson, ${ }^{[61]}$ the transition from plateau III to IV was discussed and interpreted as the formation of lath and plate martensites. The present prediction of $M_{s}$ temperatures was based on the models proposed by Stormvinter et al., ${ }^{[17]}$ who was the first to consider this phenomenon and derive two separate expressions (13) and (14) for transformation barrier.

The complexity of martensitic transformation, scarce availability of experimental $M_{s}$ temperatures and uncertainty of thermodynamic database at low temperature make it challenging when performing prediction of $M_{s}$ temperature. In the Fig. 8, 9 and 10, for the prediction of $M_{s}$ temperatures in the quaternary system of Fe-Mn-Al-C, a general trend was predicted. However, due to lack of experimental data, we had the challenge to validate the predictability. It would be interesting to have more data to assist the validation work. Another problem is that the current thermodynamic databases are not valid down to $0 \mathrm{~K}$. Thus, it is challenging to predict the $M_{s}$ temperatures for the alloys with high $\mathrm{Mn}$ and $\mathrm{Al}$ contents, which indicate low $M_{s}$ temperatures or even close to the absolute zero point.

\section{Conclusions}

A tailor-made thermodynamic database for the Fe-Mn-AlC system was developed within the LIGHTOUGH project. Thermodynamic descriptions of fcc, bcc and kappa in the database were improved. Based on the database and available experimental $M_{s}$ temperatures, the model parameters in the $M_{s}$ property model in the Thermo-Calc software ${ }^{[21]}$ were optimised. Experimental $M_{s}$ temperatures of $\mathrm{Fe}-\mathrm{C}, \mathrm{Fe}-\mathrm{Mn}$ binary systems and some alloys in $\mathrm{Fe}-\mathrm{Mn}$ $\mathrm{C}$ and $\mathrm{Fe}-\mathrm{Mn}-\mathrm{Al}$ ternary systems were well reproduced by the calculations using the newly evaluated parameters. Additional experimental $M_{s}$ temperatures for the Fe-MnAl-C quaternary system are needed to further optimise the description. The current thermodynamically based semiempirical method may be the best available approach for the prediction of $M_{s}$ temperatures. 


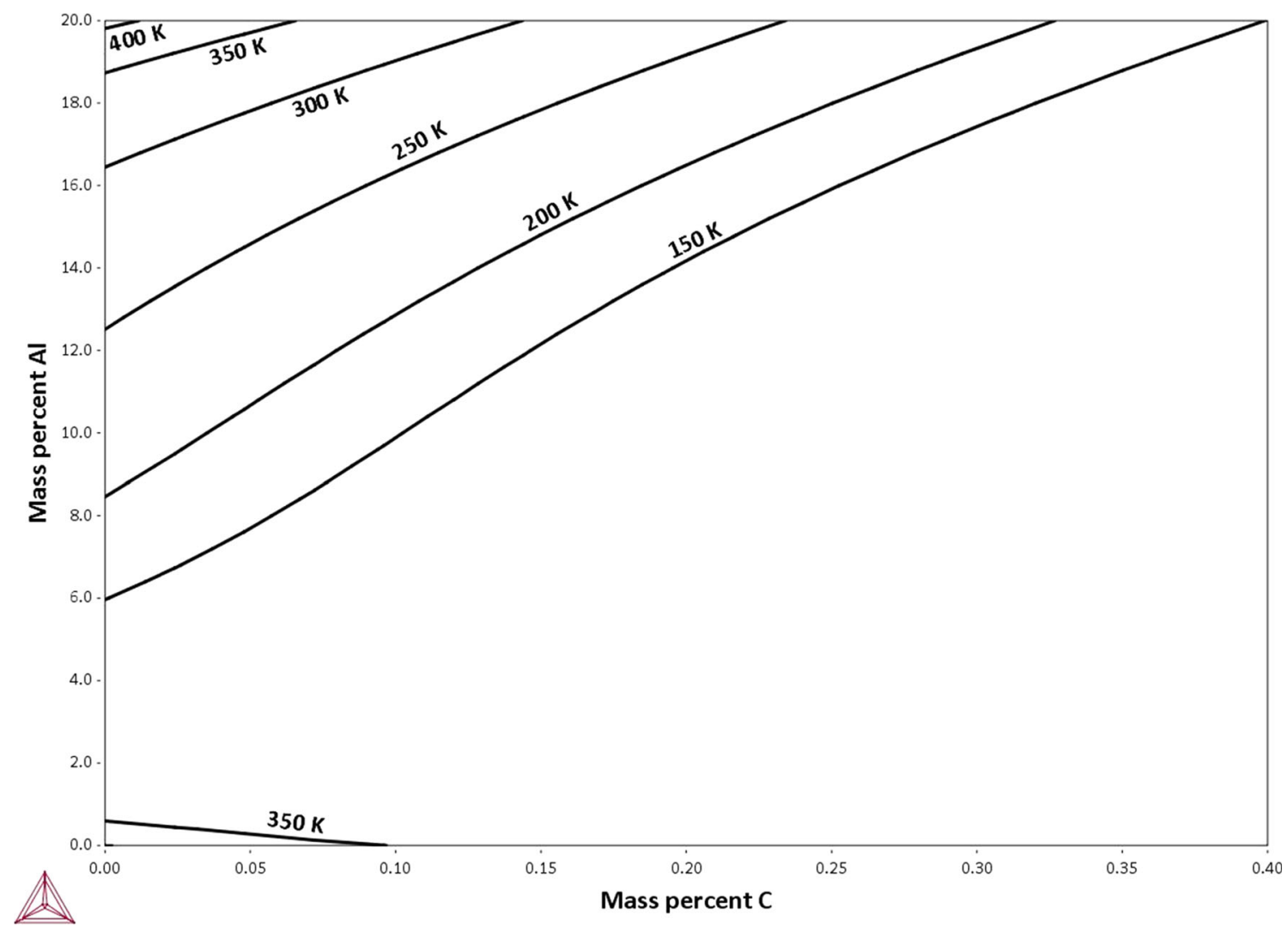

Fig. 10 Predicted $M_{s}$ temperatures for the alloy of Fe-20 wt.\% Mn- $x \mathrm{Al}-y \mathrm{C}$

Acknowledgment Zhang and Selleby would like to acknowledge Dr. Bengt Hallstedt for providing information on $M_{s}$ temperatures. Zhang appreciates the technical support from Drs. Ralf Rettig and Johan Jeppsson from Thermo-Calc Software AB. Valuable discussions with M.Sc. Arun Kumar are appreciated. The authors acknowledge the support from the RFCS LIGHTOUGH project (RFSR-CT-201500015). Some texts in the present work are based on the annual report (2017) of the LIGHTOUGH project submitted to the European Commission.

Open Access This article is distributed under the terms of the Creative Commons Attribution 4.0 International License (http://creative commons.org/licenses/by/4.0/), which permits unrestricted use, distribution, and reproduction in any medium, provided you give appropriate credit to the original author(s) and the source, provide a link to the Creative Commons license, and indicate if changes were made.

\section{References}

1. R. Howell and D.V. Aken, A Literature Review of Age Hardening Fe-Mn-Al-C Alloys, Iron Steel Technol., 2009, 6, p 193212

2. H. Kim, D. Suh, and N. Kim, Fe-Al-Mn-C Lightweight Structural Alloys: A Review on the Microstructures and Mechanical Properties, Sci. Technol. Adv. Mater., 2013, 14, p 1-11

3. D. Suh and N. Kim, Low-density Steels, Scr. Mater., 2013, 68(6), p 337-338

4. G. Frommeyer and U. Brüx, Microstructures and Mechanical Properties of High-strength Fe-Mn-Al-C Light-Weight TRIPLEX Steels, Steel Res. Int., 2006, 77, p 627-633
5. I. Kalashnikov, A. Shalkevich, O. Acselrad, and L.C. Pereira, Chemical Composition Optimization for Austenitic Steels of the Fe-Mn-Al-C System, J. Mater. Eng. Perform., 2000, 9(6), p $597-$ 602

6. Y. Sutou, N. Kamiya, R. Umino, I. Ohnuma, and K. Ishida, Highstrength Fe-20Mn-Al-C-based Alloys with Low Density, ISIJ Int., 2010, 50, p 893-899

7. D. Raabe, H. Springer, I. Gutierrez-Urrutia, F. Roters, M. Bausch, J.-B. Seol, M. Koyama, P.-P. Choi, and K. Tsuzaki, Alloy Design, Combinatorial Synthesis, and Microstructure-Property Relations for Low-Density Fe-Mn-Al-C Austenitic Steels, JOM, 2014, 66(9), p 1845-1856

8. S. Chen, R. Rana, A. Haldar, and R. Ray, Current State of Fe-MnAl-C Low Density Steels, Prog. Mater Sci., 2017, 89, p 345-391

9. J. Choi, Y. Park, I. Han and J. Morris Jr., High Manganese Austenitic Steel for Cryogenic Applications, in The 22nd International Offshore and Polar Engineering Conference (Rhodes, Greece, 17-22 June 2012)

10. C. Seo, K. Kwon, K. Choi, K. Kim, J. Kwak, S. Lee, and N. Kim, Deformation Behaviour of Ferrite-Austenite Duplex Lightweight Fe-Mn-Al-C Steel, Scr. Mater., 2012, 66, p 519-522

11. S. Park, B. Hwang, K. Lee, T. Lee, D. Suh, and H. Han, Microstructure and Tensile Behaviour of Duplex Low-density Steel Containing 5 mass\% Aluminum, Scr. Mater., 2012, 68, p 365-369

12. D. Suh, S. Park, T. Lee, C. Oh, and S. Kim, Influence of Al on the Microstructural Evolution and Mechanical Behaviour of Lowcarbon, Manganese Transformation-induced-plasticity Steel, Metall. Mater. Trans. A, 2012, 41A, p 397-408

13. L. Falat, A. Schneider, G. Sauthoff, and G. Frommeyer, Mechanical Properties of Fe-Al-M-C (M = Ti, V, Nb, Ta) Alloys 
with Strengthening Carbides and Laves Phase, Intermetallics, 2005, 13, p 1256-1262

14. S. Curtze, V. Kuokkala, A. Oikari, J. Talonen, and H. Hänninen, Thermodynamic Modelling of the Stacking Fault Energy of Austenitic Steels, Acta Mater., 2011, 59, p 1068-1076

15. G. Olson, M. Cohen, and A. General, Mechanism of Martensitic Nulceation, Part I. General Concepts and the FCC to HCP Transformation, Metall. Mater. Trans. A, 1976, 7A, p 1897-1904

16. L. Remy and A. Pineau, Twinning and Strain-induced F.C.C. H.C.P. Transformation in the Fe-Mn-Cr-C System, Mater. Sci. Eng., 1977, 28, p 99-107

17. A. Stormvinter, A. Borgenstam, and J. Ågren, Thermodynamically Based Prediction of the Martensite Start Temperature for Commercial Steels, Metall. Mater. Trans. A, 2012, 43A, p 38703879

18. L. Kaufman and M. Cohen, Thermodynamics and Kinetics of Martensitic Transformations, Prog. Metal Phys., 1958, 7, p 165246

19. M. Palumbo, Thermodynamics of Martensitic Transformations in the Framework of the CALPHAD Approach, CALPHAD, 2008, 32, p 693-708

20. A. Baruj, S. Cotes, M. Sade, and A.F. Guillermet, Effects of Thermal Cycling on the FCC/HCP Martensitic Transformation Temperatures in Fe-Mn Alloys, Z. Metallkd., 1996, 87, p 765-772

21. J. Andersson, T. Helander, L. Höglund, P. Shi, and B. Sundman, Thermo-Calc and DICTRA, Computational Tools for Materials Science, CALPHAD, 2002, 26, p 273-312

22. B. Lindahl and M. Selleby, The Al-Fe-Mn System Revisited: An Updated Thermodynamic Description Using the Most Recent Binaries, CALPHAD, 2013, 43, p 86-93

23. B. Lindahl, B. Burton, and M. Selleby, Ordering in Ternary BCC Alloys Applied to the Al-Fe-Mn System, CALPHAD, 2013, 51, p 211-219

24. B. Hallstedt, A. Khvan, B. Lindahl, M. Selleby, and S. Liu, PrecHiMn-4: A Thermodynamic Database for High-Mn Steels, CALPHAD, 2017, 56, p 49-57

25. S. Balanetskyy, D. Pavlyuchkov, T. Velikanova, and B. Grushko, The Al-rich Region of the Al-Fe-Mn Alloy System, J. Alloys Compd., 2015, 619, p 211-220

26. P. Priputen, I. Cernickova, P. Lejcek, D. Janičkovič, and J. Janovec, A Partial Isothermal Section at $1000{ }^{\circ} \mathrm{C}$ of $\mathrm{Al}-\mathrm{Mn}-\mathrm{Fe}$ Phase Diagram in Vicinity of Taylor Phase and Decagonal Quasicrystal, J. Phase Equilib. Diffus., 2016, 37, p 130-134

27. W. Zheng, S. He, M. Selleby, Y. He, L. Li, X. Lu, and J. Ågren, Thermodynamic Assessment of the Al-C-Fe System, CALPHAD, 2017, 58, p 34-49

28. W. Zheng, H. Mao, X. Lu, Y. He, L. Li, M. Selleby, and J. Ågren, Thermodynamic Investigation of the Al-Fe-Mn System Over the Whole Composition and Wide Temperature Ranges, J. Alloys Compd., 2018, 742, p 1046-1057

29. K. Chin, H. Lee, J. Kwak, J. Kang, and B. Lee, Thermodynamic Calculation on the Stability of ( $\mathrm{Fe}, \mathrm{Mn}) 3 \mathrm{AlC}$ Carbide in High Aluminum Steels, J. Alloys Compd., 2010, 505, p 217-223

30. M. Kim and Y. Kang, Thermodynamic Modeling of the Fe-Mn-C and the Fe-Mn-Al, J. Phase Equilib. Diffus., 2015, 36, p 453-470

31. I. Bajenova, I. Fartushna, A. Khvan, V. Cheverikin, D. Ivanov, and B. Hallstedt, Experimental Investigation of the Al-Mn-C System: Part I. Phase Equilibria at 1200 and $1100^{\circ} \mathrm{C}, \mathrm{J}$. Alloys Compd., 2016, 700, p 238-246

32. I. Bajenova, I. Fartushna, and A. Khvan, Experimental Investigation of the Al-Mn-C System. Part II: Liquidus and Solidus Projections, J. Alloys Compd., 2017, 695, p 3445-3456

33. W. Zheng, X. Lu, H. Mao, Y. He, M. Selleby, L. Li, and J. Ågren, Thermodynamic Modeling of the Al-C-Mn System Supported by Ab Initio Calculations, CALPHAD, 2018, 60, p 222-230
34. A. Phan, M. Paek, and Y. Kang, Phase eEquilibria and Thermodynamics of the Fe-Al-C System: Critical Evaluation, Experiment and Thermodynamic Optimization, Acta Mater., 2014, 79, p 1-15

35. M. Palm and G. Inden, Experimental Determination of Phase Equilibria in the Fe-Al-C System, Intermetallics, 1995, 3, p 443-454

36. D. Connetable, J. Lacaze, and P. Maugis, A Calphad Assessment of Al-C-Fe System with the $\kappa$ Carbide Modelled as An Ordered Form of the FCC Phase, CALPHAD, 2008, 32, p 361-370

37. W. Huang, A Thermodynamic Assessment of the Fe-Mn-C System, Metall. Trans. A, 1990, 21(8), p 2115-2123

38. E. Schürmann and I. Geissler, Melting Equilibria of the Ternary Systems Iron-Manganese-Carbon, Giessereiforschung, 1977, 29(4), p 153-159

39. D. Djurovic, B. Hallstedt, and J.V. Appen, Thermodynamic Assessment of the Fe-Mn-C System, CALPHAD, 2011, 35, p 479491

40. A. Borgenstam and M. Hillert, Driving Force for FCC to Bcc Martensites in Fe-X Alloys, Acta Mater., 1997, 45, p 2079-2091

41. M. Peet, Prediction of Martensite Start Temperature, Mater. Sci. Technol., 2014, 31, p 1370-1375

42. M. Izumiyama, M. Tsuchiya, and Y. Imai, Effects of Alloying Element on Supercooled A3 Transformation of Iron, J. Jpn. Inst. Metals, 1970, 34, p 105-115

43. J. Wang, P.V.D. Wolk, and S.V.D. Zwaag, Determination of Martensite Start Temperature in Engineering Steels Part I. Empirical Relations Describing the Effect of Steel Chemistry, Mater. Trans., JIM, 2000, 41, p 761-768

44. A. Forsberg and J. Agren, Thermodynamic Evaluation of the FeMn-Si System and the $\gamma / \varepsilon$ Martensitic Transformation, J. Phase Equilib., 1993, 14(3), p 354-363

45. S. Cotes, A.F. Guillermet, and M. Sade, Phase Stability and FCC/ HCP Martensitic Transformation in Fe-Mn-Si Alloys, Part II. Thermodynamics Modelling of the Driving Forces and the $M_{s}$ and $\mathrm{A}_{\mathrm{f}}$ Temperatures, J. Alloys Compd., 1998, 280, p 168-177

46. D. Mirzayev, M. Shteynberg, T. Ponomareva, and V.M. Schastlivtsev, The Effect of Cooling Rates on the Position of Martensite Transformation Points in Carbon Steels, Phys. Metals Metallogr., 1980, 47, p 102-111

47. A.B. Greninger and A.R. Troiano, Kinetics of the Austenite to Martensite Transformation in Steel, Trans. ASM, 1942, 28, p 537574

48. T. Hsu and H. Chang, On Calculation of $\mathrm{M}_{\mathrm{S}}$ and Driving Force for Martensitic Transformation in Fe-C, Acta Metall., 1984, 32, p 343-348

49. M. Oka and H. Okamoto, Swing Back in Kinetics Near $M_{s}$ in Hypereutectoid Steels, Metall. Mater. Trans. A, 1988, 19A, p 447-452

50. M.M. Shteynberg and D. Mirzaev, Gamma to Alpha Transformation of Fe-Mn Alloys During Cooling, Phys. Metals Metallogr., 1977, 43, p 143-149

51. S. Cotes, M. Sade, and A.F. Guillermet, FCC/HCP Martensitic Transformation in the Fe-Mn System: Experimental Study and Thermodynamic Analysis of Phase Stability, Metall. Mater. Trans. A, 1995, 26A, p 1957-1969

52. A.P. Gulyaev, T.F. Volynova, and I.Y. Georgiyeva, Phase Trasnformations in High Purity, Metal Sci. Heat Treatment, 1978, 20, p $179-182$

53. C. Choi, J. Kim, T.H. Cho, S. Baik and G.H. Ryu, Damping Capacities in Fe-X\%Mn Martensitic Alloys, in Proceedings of the Internation Conference on Martensitic Transformations (ICOMAT-92) (Monterey, California, USA, 1992), p. $509-514$

54. J.S. Choi, S.H. Baek, and J.D. Kim, Fe-Mn Group Vibration Damping Alloyg Manufacturing Method Thereof, United States Patent 5290372A, 1994 
55. J. Kim, D. Han, and S. Baik, Effects of Alloying Elements on Martensitic Transformation Behavior, Mater. Sci. Eng., A, 2004, 378, p 323-327

56. Y. Lee, Effects of Nitrogen on $\gamma \rightarrow \varepsilon$ Martensitic Transformation and Damping Capacity of Fe-16\% Mn-X\%N Alloys, J. Mater. Sci. Lett., 2002, 21, p 1149-1151

57. S. Baik, J. Kim, and K. Jee, Transformation Behavior and Damping capacity in $\mathrm{Fe}-17 \% \mathrm{Mn}-\mathrm{X} \% \mathrm{C}-\mathrm{Y} \% \mathrm{Ti}$ Alloy, ISIJ Int., 1997, 5, p 519-522

58. M. Koyama, T. Swaguchi, and T. Lee, Work Hardening Associated with $\varepsilon$-Martensitic Transformation, Deformation Twinning and Dynamic Strain Aging in Fe-17Mn-0.6C and Fe-17Mn-0.8C TWIP Steels, Mater. Sci. Eng., A, 2011, 528, p 7310-7316

59. K. Ishida and T. Nishizawa, Effect of Alloying Elements on Stability of Epsilon Iron, J. Jpn. Inst. Metals, 1974, 15, p 225231, in Japanese

60. D.A. Mirzayev, V.M. Schastlivtsev, and S. Karzunov, Martensite Points of Fe-C Alloys, Fiz. Met. Metalloved., 1987, 63, p 764-767

61. E. Wilson, The $\gamma \rightarrow \alpha$ Transformation in Low Carbon Irons, ISIJ Int., 1994, 34, p 615-630 